\title{
Impact of composting strategies on the degradation of nonylphenol in sewage sludge
}

\author{
Guodi Zheng $^{1} \cdot$ Tongbin Chen $^{1} \cdot$ Jie $\mathrm{Yu}^{1} \cdot$ Ding Gao $^{1} \cdot$ Yujun Shen ${ }^{1} \cdot$ \\ Mingjie Niu ${ }^{1} \cdot$ Hongtao Liu ${ }^{1}$
}

Accepted: 24 September 2015/Published online: 9 October 2015

(C) Springer Science+Business Media New York 2015

\begin{abstract}
Nonylphenol can be present in sewage sludge, and this can limit the use of the sewage sludge to amend soil. Composting is one of the most efficient and economical methods of making sewage sludge stable and harmless. The nonylphenol degradation rates during composting with added bulking agents and with aeration applied were studied. Three organic bulking agents (sawdust, corn stalk, and mushroom residue) were added to sewage sludge, and the effects of the bulking agents used and the amount added on nonylphenol degradation were determined. The highest apparent nonylphenol degradation rate $(71.6 \%)$ was found for sewage sludge containing $20 \%$ mushroom residue. The lowest apparent nonylphenol degradation rate $(22.5 \%)$ was found for sewage sludge containing $20 \%$ sawdust. The temperature of the composting pile of sewage sludge containing $20 \%$ sawdust became too high for nonylphenol to be efficiently degraded, and the apparent nonylphenol degradation rate was lower than was found for sewage sludge containing $10 \%$ sawdust. Increasing the ventilating time from 5 to $15 \mathrm{~min}$ increased the apparent nonylphenol degradation rate from 19.7 to $41.6 \%$. Using appropriate aerobic conditions facilitates the degradation of nonylphenol in sewage sludge, decreasing the risks posed by sewage sludge applied to land. Adding too much of a bulking agent can decrease the amount of the nonylphenol degraded. Increasing the ventilating time and the amount of air supplied can increase the amount of nonylphenol degraded
\end{abstract}

Guodi Zheng

zhenggd@igsnrr.ac.cn

1 Center for Environmental Remediation, Institute of Geographic Sciences and Natural Resources Research, Chinese Academy of Sciences, Beijing 100101, China even if doing so causes the composting pile temperature to remain low.

Keywords Nonylphenol · Degradation - Compost · Sewage sludge $\cdot$ Bulking agent $\cdot$ Aeration

\section{Introduction}

The number and total capacity of municipal wastewater treatment plants in China have increased very rapidly in the past 20 years, and more than $30 \times 10^{6} \mathrm{t}$ of sewage sludge (with a water content of $80 \%$ ) was produced in 2013. Applying sewage sludge to land has been seen as a practical way of disposing of the sewage sludge produced in China, and it has until now been the preferred disposal method (Zheng et al. 2007). However, environmental awareness is increasing, and this has led to a great deal of attention being paid to the risks involved in reusing sewage sludge, especially the risks posed by organic pollutants in the sewage sludge (Scott-Fordsmand and Krogh 2004; Eriksson et al. 2008; Sui et al. 2009; Chen et al. 2012). Nonylphenol (NP) has a chemical structure that is very similar to the structures of human and other animal hormones, therefore it can interfere with normal endocrine and psychological functions (affecting reproduction and development) when it is present in the body ( $\mathrm{Li}$ et al. 2012). Interest in controlling the exposure of humans and animals to NP has therefore recently been increasing (Harvey et al. 2002; Abad et al. 2005; Ying. 2006; Venkatesan and Halden 2013). NP present in the environment is mainly derived from nonylphenol ethoxylates (NPEs) which are nonionic surfactants that are used in a wide range of industrial processes and consumer products (Arslan and Parlak 2007). NPEs is discharged in sewage 
water and are then converted into NP, which is more persistent and poisonous than NPEs and accumulates in sewage sludge (Capota et al. 2004; Fountoulakis et al. 2005; Kim et al. 2007; Arditsoglou and Voutsa 2008; Zhang et al. 2008). The production and use of NP and NPEs is currently restricted or banned in Canada, the EU, Japan, and the USA, but NPEs are still used in large amounts in China (Harrison et al. 2006; Soares et al. 2008). Qiao et al. (2007) conducted a 3-years study of wastewater treatment plants in China and found NP in all of the sewage sludge samples that were analyzed, the NP content being $1.00-128.45 \mathrm{mg} /$ $\mathrm{kg}$. Hao et al. (2007) found an NP content of $177.7 \mathrm{mg} / \mathrm{kg}$ in sewage sludge from the concentrated sludge tank of a Beijing wastewater treatment plant. Lian et al. (2009) found NP contents of $149.6-167.2 \mathrm{mg} / \mathrm{kg}$ in digested sludge from four wastewater treatment plants in Beijing. It appears that NP can be detected in sludge from most or all wastewater treatment plants in China, and it has been found at higher contents in Chinese sewage sludge than in sewage sludge from EU countries (Harrison et al. 2006; Soares et al. 2008). There is currently no statutory limit on the NP content of sewage sludge applied to land in China. However, the EU limit for NP in sewage sludge is $50 \mathrm{mg} / \mathrm{kg}$, indicating that applying Chinese sewage sludge to land will lead to risks to the environment being posed by the presence of NP.

Biodegradation is the final mechanism through which organic pollutants can be removed from the natural environment (Lu et al. 2008). Research into the biodegradation of organic pollutant has been focused on NP degradation in the environment for the past few years. The degradation of organic pollutant during the sewage sludge fermentation process is affected not only by the characteristics of the pollutants but also by the $\mathrm{pH}, \mathrm{C} / \mathrm{N}$ ratio, water content, oxygen content and temperature of the system (Li et al. 2007; Lashermes et al. 2010). Studies of NP biodegradation processes and the factors that influence the processes have been performed (Chang et al. 2008; Soares et al. 2008; Zhang et al. 2008; Chang et al. 2009). However, most of these studies have been performed using river sediments, sewage water, or soil. Little research has been performed on NP degradation during the sewage sludge composting process.

Composting is the most common treatment for sewage sludge before the sludge is applied to land. It has been found that some organic pollutants are significantly degraded by microorganisms during high-temperature aerobic fermentation (Oleszczuk 2006; Haritash and Kaushik 2009; Pakou et al. 2009). It is therefore necessary to examine the factors that influence NP degradation during aerobic fermentation so that composting processes can be optimized. This would allow the degradation of NP in sewage sludge to be facilitated and decrease the risks posed by applying sewage sludge to land.
Das and Xia (2008) found that adding wood shavings facilitated NP degradation during the composting process, and found that $80 \% \mathrm{NP}$ was degraded when the sewage sludge was mixed with a high proportion of wood shave (to give a $\mathrm{C} / \mathrm{N}$ 65:1). Similar results have been found for other organic pollutants. Hua et al. (2008) found that the proportion of polycyclic aromatic hydrocarbons that were degraded was related to the organic matter content of the sludge. The studies mentioned above showed that organic matter facilitates NP degradation, but further research is required to determine the effectiveness with which NP degradation can be achieved using different bulking agents and to determine the optimum amounts of the bulking agents to add.

Most studies of NP degradation during the sewage sludge composting process have been carried out using small simulation devices. In such studies, heat is added to maintain the temperature of the sewage sludge composting pile. However, unlike in simulations the activities of the microorganisms produce all of the heat involved in the composting process under real composting conditions. The results of simulation experiments therefore have limited practice applicability.

Although it has been found that NP is degraded when sewage sludge is composted, no systematic study of the effects of aeration and other factors on NP degradation during composting has yet been performed. Most studies of $\mathrm{NP}$ degradation during aerobic fermentation have been limited to investigating the influences of a specific factors, rather than the influences of multiple factors, using simulation experiments. A comprehensive study of multiple factors that influence NP degradation during the composting process is required. Any factor that can affect the development and reproduction of microorganisms may influence the degradation of organic pollutants in sewage sludge. Factors that affect the sewage sludge composting process, such as the air supply and the temperature, humidity, $\mathrm{pH}$, water content, and $\mathrm{C} / \mathrm{N}$ ration of the system, will clearly influence the degradation and transformation of organic pollutants during composting. Techniques for controlling the sewage sludge composting conditions are now well developed, making it possible to identify the effects of different aerobic composting parameters on NP degradation. We aimed to identify the optimum conditions for NP to be degraded during the composting of sewage sludge. In the study presented here, we determined the proportion of the NP in sewage sludge that was degraded in a high-temperature aerobic composting system operated under different conditions. The factors influencing the composting process, including the type and amount of bulking agent added and the ventilation strategies, were closely controlled. The ultimate aim was to allow the risks posed by the application of sewage sludge to land to be 
decreased by using appropriate aerobic composting strategies while sewage sludge is matured.

\section{Materials and methods}

\section{Experimenting devices}

The experiment was conducted using an enclosed aerobic fermentation reactor. The reactor was a cylinder with an outer and an inner layer, with a layer of thermal insulation between the layers. The inside layer diameter was $600 \mathrm{~mm}$, the outside layer diameter was $800 \mathrm{~mm}$, and the cylinder was $1010 \mathrm{~mm}$ tall. The ventilation process was controlled by an automatic control system with an industrial control computer and automatic aerobic fermentation management control software (Fig. 1). The temperature of the composting pile was determined in real time using a probe in the pile. The reactor, fan, temperature probe, and automatic control system in the aerobic fermentation process simulation device were connected as shown in Fig. 1. Data (such as the ventilation timing, temperature, and ventilation frequency) were recorded in real time and stored by the industrial control computer.

\section{Experimental design}

Different types and amounts of bulking agents were added to sewage sludge, and the mixtures were composted in the apparatus described above. The sewage sludge was collected from the Beijing Gaobeidian wastewater treatment plant, and had a water content of $81.6 \%$ and an organic matter of $50.2 \%$ of the solid matter. The bulking agents were sawdust, corn stalks and mushroom residue, the particles sizes of which were $0.1-0.2,0.5-1$ and $0.1-0.5 \mathrm{~cm}$, respectively. The water contents of the sawdust, corn stalks, and mushroom residue were $6.83,7.18$ and $27.4 \%$, respectively. The sewage sludge was mixed with a bulking agent at a ratio of $5: 1(\mathrm{w} / \mathrm{w})$. The composting period was 20 days. The ventilation cycle was $30 \mathrm{~min}$, and a cycle involved $10 \mathrm{~min}$ continuous ventilation followed by $20 \mathrm{~min}$ without ventilation. The physiochemical properties of the initial mixtures used in the experiments are given in Table 1.

Experiments were also performed using different ventilation strategies. The sewage sludge used in these tests was also collected from the Beijing Gaobeidian wastewater treatment plant, and it had a water content of $77.3 \%$ and an organic matter content of $54.3 \%$ of the solid matter. The sewage sludge was mixed with sawdust that had a particle size of $0.1-0.2 \mathrm{~cm}$, a water content of $6.83 \%$, and an organic matter content of $67.4 \%$ of the dry matter. The sewage sludge to sawdust ratio was 5:1 (w/w), and the mixture had an organic matter content of $63.7 \%$ of the dry matter and a water content of $65.1 \%$. The ventilation cycle lasted $30 \mathrm{~min}$, and the ventilation rate was $0.05-0.1 \mathrm{~m}^{3} / \mathrm{min}$. The ventilation strategies that were used in the three treatments are shown in Table 2. The composting period was 20 days.

\section{Analysis methods}

A 100-g aliquot of sewage sludge was freeze dried, then it was ground and passed through a 1-mm sieve. An aliquot of exactly $1.000 \mathrm{~g}$ of the dry sample was placed in a $50-\mathrm{mL}$ conical flask with lid, then $50 \mathrm{ml}$ of a 1:1 (v/v) mixture of acetone and $n$-hexane was added to the flask, and the mixture was left for $30 \mathrm{~min}$. The flask was then placed in an ultrasonic extraction unit for $30 \mathrm{~min}$, then the sediment was allowed to settle. The supernatant was transferred to a new flask, and $2.5 \mathrm{~mL}$ of isooctane was added before the extract was concentrated to approximately $15 \mathrm{~mL}$ using a rotary evaporator. The liquid was shaken well and dried with anhydrous sodium sulfate until no remaining water could be seen. The extract was then concentrated to $5 \mathrm{~mL}$ using a rotator evaporator, filtered through anhydrous

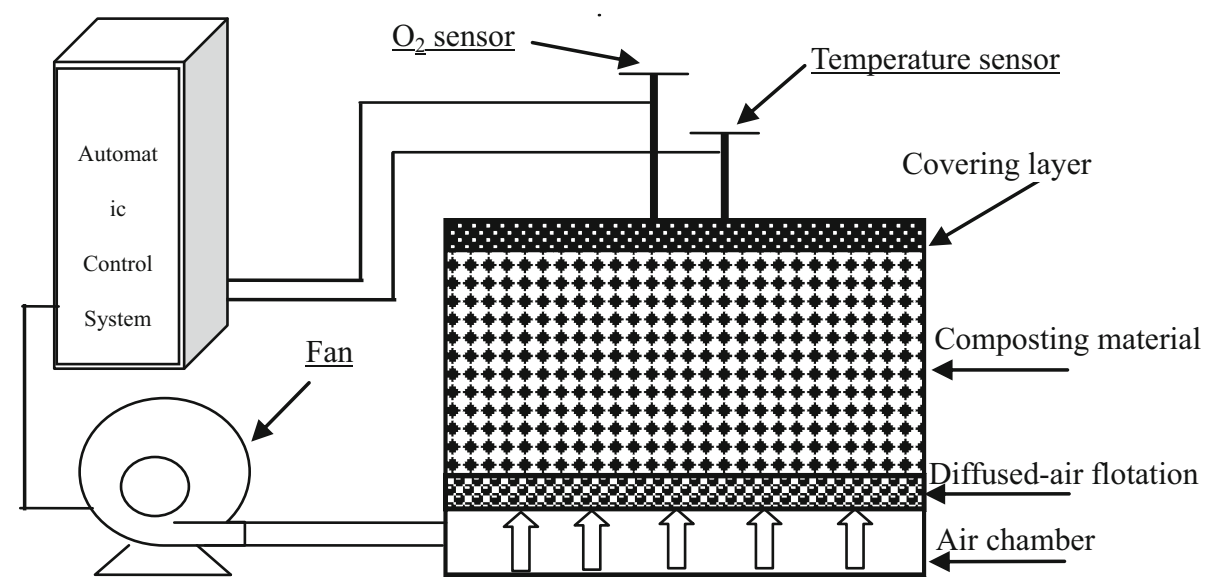

Fig. 1 Sewage sludge composting device used in the experiments 
Table 1 Physiochemical properties of the initial mixtures of sewage sludge and the bulking agents

\begin{tabular}{llllr}
\hline Treatment & Treatment no. & Water content $\%$ & Organic matter $\%$ & C/N ratio \\
\hline Sludge:sawdust $=5: 1$ & SS20 & 69.1 & 60.2 & 8.2 \\
Sludge:corn stalks $=5: 1$ & SC20 & 69.2 & 60.1 & 13.2 \\
Sludge:mushroom residue $=5: 1$ & SM20 & 72.6 & 50.6 & 11.2 \\
Sludge:sawdust $=10: 1$ & SS10 & 74.8 & 49.9 & 7.0 \\
\hline
\end{tabular}

\begin{tabular}{lll}
\hline Treatment no. & Ventilation cycle length $(\mathrm{min})$ & Ventilation strategy \\
\hline A5 & 30 & 5 min continuous ventilation, 25 min interval \\
A10 & 30 & 10 min continuous ventilation, 20 min interval \\
A15 & 30 & 15 min continuous ventilation, 15 min interval \\
\hline
\end{tabular}

Table 2 Ventilation strategies used in the sewage sludge composting tests to determine the effects of different levels of air supply piles, and reached $45^{\circ} \mathrm{C}$ after 0.6 days. The mesophilic phase of the SM20 composting pile was complete after 1.1 days. The SS10, SS20, SC20, and SM20 composting piles all remained at $50{ }^{\circ} \mathrm{C}$ until more than 5 days had passed, meeting the requirement given in the Chinese "Sanitary standard for the non-hazardous treatment of night soil" (GB7959-87) that a composting pile should remain at $50-55{ }^{\circ} \mathrm{C}$ or higher for 5-7 days.

The temperatures of the SS10 and SS20 composting piles indicated that the composting process had been completed by the end of the study. The SS10 composting pile remained above $50{ }^{\circ} \mathrm{C}$ for 6 days, and the SS20 composting pile remained above $50{ }^{\circ} \mathrm{C}$ for 7 days.

\section{Effects of adding different bulking agents on NP degradation}

The NP content of the sludge was $26 \mathrm{mg} / \mathrm{kg}$, and it was diluted to $12.9 \mathrm{mg} / \mathrm{kg}$ when the sludge was mixed with $20 \%$ sawdust. The NP content had decreased to $10 \mathrm{mg} / \mathrm{kg}$ after the sludge mixed with $20 \%$ sawdust had been aerobically composted for 20 days, giving an apparent degradation rate $(\mathrm{ADR})$ of $22.5 \%$.

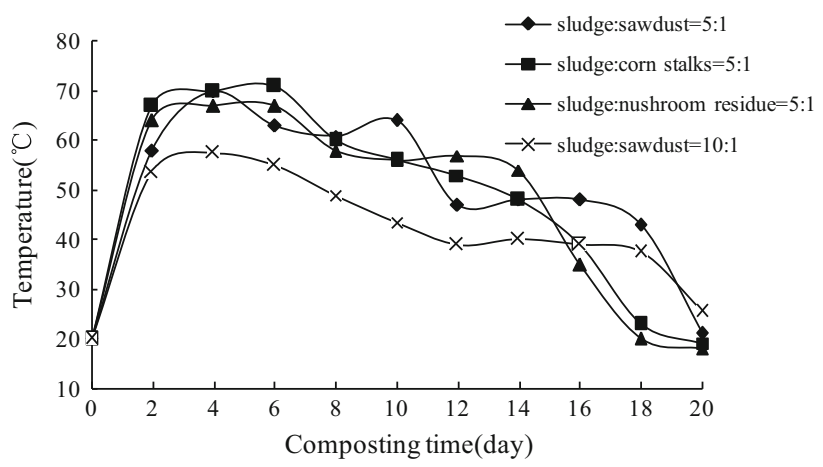

Fig. 2 Temperatures in the composting piles of sewage sludge mixed with different bulking agents during the composting process 
The NP content of the sewage sludge mixed with $20 \%$ corn stalks started at $12.9 \mathrm{mg} / \mathrm{kg}$ and had decreased to $6 \mathrm{mg} / \mathrm{kg}$ after 20 days of aerobic composting, giving an ADR of $53.5 \%$. The ADR was better for the sewage sludge mixed with $20 \%$ corn stalks than for the sewage sludge mixed with $20 \%$ sawdust. The NP content of the sewage sludge mixed with $20 \%$ mushroom residue started at $21.1 \mathrm{mg} / \mathrm{kg}$ and had decreased to $6 \mathrm{mg} / \mathrm{kg}$ after 20 days of aerobic composting, giving an ADR of $71.6 \%$ (Fig. 3).

The NP was degraded more effectively during the composting period in the sewage sludge mixed with mushroom residue than in the sewage sludge mixed with the other bulking agents, and the NP was least effectively degraded in the sewage sludge mixed with sawdust.

The NP content of the SS10 composting pile started at $17.3 \mathrm{mg} / \mathrm{kg}$ and had decreased to $11 \mathrm{mg} / \mathrm{kg}$ at the end of the study, giving an ADR of $36.4 \%$. The SS10 ADR was higher than the SS20 ADR. The SS10, SS20, SC20, and SM20 composting piles had different organic matter and water contents (Table 1) because of the different bulking agents or amounts of bulking agents used. The organic matter contents of the composting piles were particularly different. The organic matter content influenced the water content of each composting mixture, and the water content will have affected the effectiveness with which NP was degraded during the composting process.

The NP will have been present in the sludge in various bound states. Some of the NP will have been sorbed to low energy sorption sites and been relatively easily absorbed and used by the microorganisms (Hao et al. 2007). However, some of the NP will have been strongly adsorbed at competitive adsorption sites and been less available to the microorganisms, remaining as a residue after the composting process had been completed. Wang et al. (2011) found that a higher organic matter content in a soil generally favors NP degradation because microorganism activity increases as the organic matter content increases.

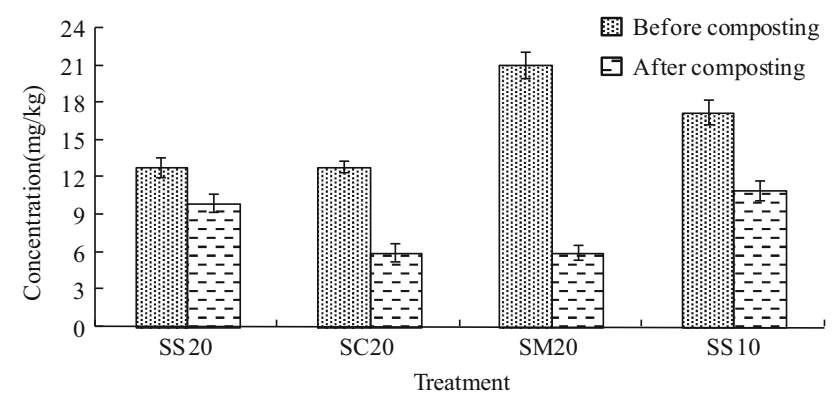

Fig. 3 Nonylphenol concentrations in the sewage sludge mixed with different bulking agents before and after composting. SS20 5:1 sludge:sawdust; SC2O 5:1 sludge:corn stalks; SM20 5:1 sludge:mushroom residue; SS10 10:1 sludge:sawdust
However, it has been found that NP is easily absorbed by sewage sludge organic matter, and this will strongly decrease the bioavailability of the NP and the proportion that can be degraded by microorganisms (Wu et al. 2006). The sewage sludge mixtures containing different proportions of sawdust had different water contents, organic matter contents, and $\mathrm{C} / \mathrm{N}$ ratios, each of which could have strongly influenced the effectiveness with which the microorganisms were able to degrade the NP. However, adding too much bulking agent was found to lead to less effective NP degradation.

The degradation of NP is also affected by the temperature of the composting pile during the composting process. The rate at which NPE degradation occurs has been found to increase as the temperature increases from 15 to $35{ }^{\circ} \mathrm{C}$ ( $\mathrm{Lu}$ et al. 2008). There is also evidence that NP degradation is inhibited when a certain temperature is reached. Moeller and Reeh (2003) performed a study in which NP was degraded at different rates at different temperature, and they found that NP accumulate quickly (i.e., NP degradation was inhibited) at $65^{\circ} \mathrm{C}$. Lashermes et al. (2010) found that NP was degraded faster at $50{ }^{\circ} \mathrm{C}$ than at other temperature and that NP degradation was inhibited at $65-75^{\circ} \mathrm{C}$ in simulated composting experiments. The evidence described above shows that increasing the temperature can facilitate NP degradation. However, the temperature at which NP is degraded most effectively under real composting conditions still needs to be determined. In our tests, the sewage sludge mixed with $10 \%$ sawdust remained at a lower temperature than did the other mixtures, but NP was degraded more effectively in the sewage sludge mixed with $10 \%$ sawdust than in the other mixtures. Our results show that NP degradation was influenced by the temperature but was inhibited when the temperature was too high.

\section{Effects of different ventilation strategies on the temperature in a composting pile}

Ventilation is a key factor in the aerobic composting process. Appropriate ventilation will allow sufficient oxygen to be supplied to the mixture to allow the temperature to change in an optimum way. An insufficient supply of oxygen can cause the temperature of the composting pile to increase too slowly at the beginning of the composting process and to be too high during the high-temperature phase (Belén et al. 2010), and this will affect the ability of the composting process to detoxify the sewage sludge. The composting process was completed successfully under all three ventilation strategies that were tested (ventilating for $5 \mathrm{~min}, 10 \mathrm{~min}$, and $15 \mathrm{~min}$ in a 30 -min ventilation cycle). The composting pile temperature exceeded $50{ }^{\circ} \mathrm{C}$ for 8.8 days when 5 min ventilation was performed in each 


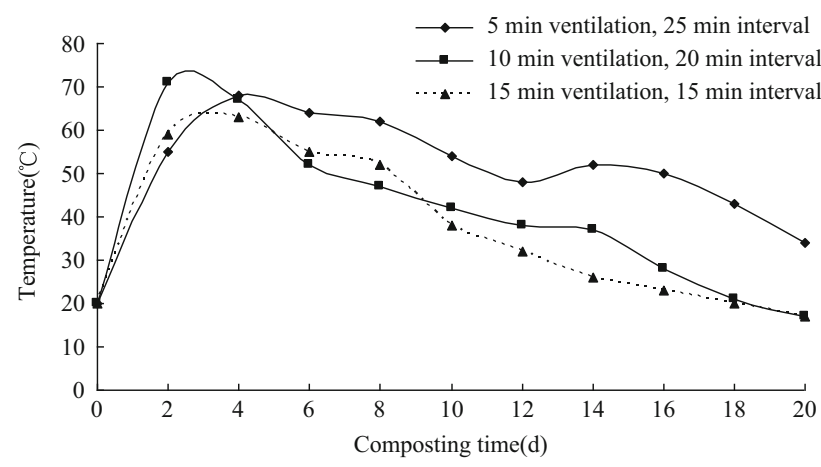

Fig. 4 Temperature of sewage sludge composting piles under different aeration programs

30-min cycle. The temperature exceeded $50{ }^{\circ} \mathrm{C}$ for 5.5 days when 10 min ventilation was performed in each 30 -min cycle, and the temperature exceeded $50{ }^{\circ} \mathrm{C}$ for 7 days when 15 min ventilation was performed in each 30-min cycle. It can be seen that the longer ventilation periods used in each ventilation cycle (i.e., supplying more air) in tests A10 and A15 caused the composting pile temperature to be lower than it was when the ventilation period was shorter (and less air was supplied) in the test A5 (Fig. 4).

\section{Influence of different compost ventilation strategies on the degradation of NP in the sewage sludge}

The NP content of the sewage sludge mixture started at $13.7 \mathrm{mg} / \mathrm{kg}$ and decreased to $11 \mathrm{mg} / \mathrm{kg}$ when the ventilation period was $5 \mathrm{~min}$ in each 30 -min ventilation cycle, giving an ADR of $19.7 \%$. The NP content decreased to $9 \mathrm{mg} / \mathrm{kg}$ when the ventilation period was $10 \mathrm{~min}$ in each 30 -min ventilation cycle, giving an ADR of $34.3 \%$. The NP content decreased to $8 \mathrm{~kg} / \mathrm{mg}$ when the ventilation period was $15 \mathrm{~min}$ in each 30-min ventilation cycle, giving an ADR of $41.6 \%$ (Fig. 5).

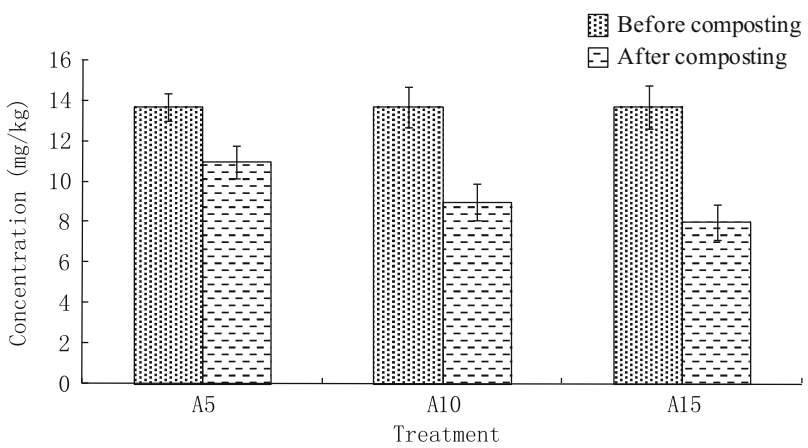

Fig. 5 Nonylphenol concentrations in the sewage sludge before and after composting using different aeration programs. A5 $5 \mathrm{~min}$ ventilation, $25 \mathrm{~min}$ interval; $A 1010 \mathrm{~min}$ ventilation, $20 \mathrm{~min}$ interval; A15 15 min ventilation, 15 min interval
According to Banat et al. (2000), ventilation facilitates the degradation of NP in sewage sludge, but in that study the sewage sludge had a water content of $99.7 \%$, which is rather higher than the water content of $80 \%$ usually found under real condition. González et al. (2010) found that more NP was degraded in an aerobic treatment than in an anaerobic treatment. However, it was found in another study that alternating aerobic and anaerobic treatments facilitated the biodegradation of organic pollutants. Patureau et al. (2008) found that a high-temperature aerobic treatment combined with a mid- or high-temperature anaerobic treatment led to the more effective biodegradation of organic pollutants than using only an aerobic or anaerobic treatment. Improving the aerobic fermentation conditions will facilitate the degradation of NP in sewage sludge. However, improving the degradation of pollutants by controlling the oxygen supply is worthy of further study. According to Yuan et al. (2004), neither aerobic nor anaerobic condition control the rate at which NP is degraded. The fact is that NP can be degraded under both aerobic and anaerobic conditions.

Our results show that different oxygen supply strategies influenced the degradation of NP during the composting process. Providing appropriate ventilation during the composting process will therefore increase the efficiency with which NP is degraded and decrease the NP content of the compost produced.

\section{Conclusion}

The proportion of NP that was biodegraded when sewage sludge was composted was higher when mushroom residue was used as a bulking agent than when sawdust or corn stalks were used as bulking agents. Adding too much bulking agent caused the temperature in the composting pile to become too high, which inhibited NP degradation. Providing a long ventilation time in each ventilation cycle, to increase the air supply, during the aerobic composting process will facilitate the degradation of NP in sewage sludge. Using an appropriate composting strategy could promote the biodegradation of NP in sewage sludge during a composting process, and could decrease the environmental risks posed by applying sewage sludge to land.

Acknowledgments This study was supported by the National Natural Science Foundation of China (Grant No. 41101463, 41371455).

\section{Compliance with ethical standards}

Conflict of interest The authors declare that they have no conflict of interest. 


\section{References}

Abad E, Martínez K, Planas C, Palacios O, Caixach J, Rivera J (2005) Priority organic pollutant assessment of sludges for agricultural purposes. Chemosphere 61(9):1358-1369

Arditsoglou A, Voutsa D (2008) Determination of phenolic and steroid endocrine disrupting compounds in environmental matrices. Environ Sci Pollut R 15(3):228-236

Arslan OC, Parlak H (2007) Embryotoxic effects of nonylphenol and octylphenol in sea urchin Arbacia lixula. Ecotoxicology 16(6):439-444

Banat FA, Prechtl S, Bischof F (2000) Aerobic thermophilic treatment of sewage sludge contaminated with 4-nonylphenol. Chemosphere 41(3):297-302

Belén P, Teresa G, Antoni S (2010) A new control strategy for the composting process based on the oxygen uptake rate. Chem Eng J 165(1):161-169

Capota CD, Deventer B, Zimmermann R-D (2004) The effect of 4-nonylphenol on the pigmentation of Ocimum basilicum (Basil). Environ Sci Pollut Res 11(2):121-125

Chang BV, Liu CL, Yuan SY, Cheng CY, Ding WH (2008) Biodegradation of nonylphenol in mangrove sediment. Int Biodeter Biodegr 61(4):325-330

Chang BV, Lu YS, Yuan SY, Tsao TM, Wang MK (2009) Biodegradation of phthalate esters in compost-amended soil. Chemosphere 74(6):873-877

Chen H, Yan S-H, Ye Z-L, Meng H-J, Zhu Y-G (2012) Utilization of urban sewage sludge: Chinese perspectives. Environ Sci Pollut Res 19(5):1454-1463

Das KC, Xia K (2008) Transformation of 4-nonylphenol isomers during biosolids composting. Chemosphere 70(5):761-768

Eriksson E, Christensen N, Schmidt JE, Ledin A (2008) Potential priority pollutants in sewage sludge. Desalination 226(1-3): 371-388

Fountoulakis M, Drillia P, Pakou C, Kampioti A, Stamatelatou K, Lyberatos G (2005) Analysis of nonylphenol and nonylphenol ethoxylates in sewage sludge by high performance liquid chromatography following microwave-assisted extraction. J Chromatogr A 1089(1-2):45-51

González MM, Martín J, Santos JL, Aparicio I, Alonso E (2010) Occurrence and risk assessment of nonylphenol and nonylphenol ethoxylates in sewage sludge from different conventional treatment processes. Sci Total Environ 408(3):563-570

Hao R, Liang P, Zhou Y (2007) Study on translation and conversion behavior of nonylphenol in municipal wastewater treatment China. Water Wastewater 23(1):105-108 in Chinese

Haritash AK, Kaushik CP (2009) Biodegradation aspects of Polycyclic Aromatic Hydrocarbons (PAHs): a review. J Hazard Mater 169(1-3):1-15

Harrison EZ, Oakes SR, Hysell M, Hay A (2006) Organic chemicals in sewage sludges. Sci Total Environ 367(2-3):481-497

Harvey PJ, Campanella BE, Castro PML, Harms H, Lichtfouses E, Schäffner AR, Smrcek S, Werck-Reichhart D (2002) Phytoremediation of polyaromatic hydrocarbons, anilines and phenols Environ. Sci Pollut Res 9(1):29-47

Hua L, Wu W, Liu Yu, Chen Y, McBride MB (2008) Effect of composting on polycyclic aromatic hydrocarbons removal in sewage sludge. Water Air Soil Pollut 193(1-4):259-267

Kim JY, Ryu K, Kim EJ, Choe WS, Cha GC, Yoo I-K (2007) Degradation of bisphenol $\mathrm{A}$ and nonylphenol by nitrifying activated sludge. Process Biochem 42(10):1470-1474

Lashermes G, Houot S, Barriuso E (2010) Sorption and mineralization of organic pollutants during different stages of composting. Chemosphere 79(4):455-462
Li C, Ji R, Vinken R, Hommes G, Bertmer M, Schäffer A, Corvini PFX (2007) Role of dissolved humic acids in the biodegradation of a single isomer of nonylphenol by Sphingomonas sp. Chemosphere 68(11):2172-2180

Li ZY, Zhang HL, Gibson M, Liu P (2012) An evaluation of the combined effects of phenolic endocrine disruptors on vitellogenin induction in goldfish Carassius auratus. Ecotoxicology 21(7):1919-1927

Lian J, Liu JX, Wei YS (2009) Fate of nonylphenol polyethoxylates and their metabolites in four Beijing wastewater treatment plants. Sci Total Environ 407(14):4261-4268

Lu J, Jin Q, He Y (2008) Biodegradation of nonylphenol polyethoxylates by denitrifying activated sludge. Water Res 42(4-5): 1075-1082

Moeller J, Reeh U (2003) Degradation of nonylphenol ethoxylates (NPE) in sewage sludge and source separated municipal solid waste under bench-scale composting conditions. Bull Environ Contam Toxicol 70(2):248-254

Oleszczuk P (2006) Influence of different bulking agents on polycyclic aromatic hydrocarbons (PAHs) disappearance during sewage sludge composting. Water Air Soil Poll 175(1-4):15-32

Pakou C, Kornaros M, Stamatelatou K, Lyberatos G (2009) On the fate of LAS, NPEOs and DEHP in municipal sewage sludge during composting. Bioresour Technol 100(4):1634-1642

Patureau D, Delgenes N, Delgenes J (2008) Impact of sewage sludge treatment processes on the removal of the endocrine disrupters nonylphenol ethoxylates. Chemosphere 72(4):586-591

Qiao Y, Zhang J, Zhang Y, Chen M, Yang M, Xu D (2007) Occurrence of alkylphenol and bisphenol-A in sewage sludge in a north China city. Environ Chem 6(5):671-674 (in Chinese)

Scott-Fordsmand JJ, Krogh PH (2004) The influence of application form on the toxicity of nonylphenol to Folsomia fimetaria (Collembola: Isotomidae). Ecotoxicol Environ Saf 58(3): 294-299

Soares A, Guieysse B, Jefferson B, Cartmell E, Lester JN (2008) Nonylphenol in the environment: a critical review on occurrence, fate, toxicity and treatment in wastewaters. Environ Int 34(7):1033-1049

Sui Q, Huang J, Yu G (2009) Priority analysis for controlling endocrine disrupting chemicals in municipal wastewater treatment plants of China. Environ Sci 30(2):384-390 (in Chinese)

Venkatesan AK, Halden RU (2013) National inventory of alkylphenol ethoxylate compounds in U.S. sewage sludges and chemical fate in outdoor soil mesocosms. Environ Pollut 174:189-193

Wang Y, Yang Z, Li Z, Ren H (2011) Degradation and adsorption of nonylphenol in soils. J Agroenviron Sci 30(8):1561-1566 (in Chinese)

Wu H, Liang S, Wei C (2006) Research progresses on environmental behavior and biodegradation of nonylphenol. Environ Protect Chem Ind 26(1):31-34 (in Chinese)

Ying GG (2006) Fate, behavior and effects of surfactants and their degradation products in the environment. Environ Int 32(3): $417-431$

Yuan SY, Yu CH, Chang BV (2004) Biodegradation of nonylphenol in river sediment. Environ Pollut 127(3):425-430

Zhang J, Yang M, Zhang Y, Chen M (2008) Biotransformation of nonylphenol ethoxylates during sewage treatment under anaerobic and aerobic conditions. J Environ Sci-China 20(2):135-141

Zheng GD, Gao D, Chen TB, Luo W (2007) Stabilization of nickel and chromium in sewage sludge during aerobic composting. J Hazard Mater 142(1-2):216-221 